\title{
The Development of Safety Performance Functions for Roundabouts in Amman, Jordan
}

\author{
Diana AL- Nabulsi ${ }^{1,}$ a and KhairJadaan ${ }^{2}$ \\ ${ }^{1}$ Research Assistant, Civil Engineering Department, University of Jordan \\ ${ }^{2}$ Professor, Civil Engineering Department, University of Jordan
}

\begin{abstract}
It is now well established that crash occurrences at roadway segments or intersections are associated with a large variety of factors. Safety Performance Functions (SPF) are statistical models developed to predict crash frequencies for various design variables.

In Jordan, almost half of all road crashes occur at intersections, mostly in urban areas. There is a significant number of roundabouts throughout Amman which is increasing without evaluating their safety performance. To assess safety benefits of this kind of intersections, transportation professionals need the powerful statistical tool; the SPF.

This study aims to develop SPFs for roundabouts in Amman. The models consider the crash frequency, traffic volume and geometric features of all the studied 20 roundabouts. The developed SPFs were statistically significant $\left(\mathrm{R}^{\wedge} 2=0.91\right)$. The findings of the study revealed that crash frequency has a strong relation with the AADT, roundabout entry angle-degrees, entry path radius, splitter radius, pedestrian crossing structure, inscribed diameter, central diameter, circulating width, entry width, number of circle legs. The developed SPFs are evaluated through a comparison with others from developed countries.
\end{abstract}

\section{Introduction}

Road traffic safety has become an intensively researched topic with the aim of enabling the road authorities to identify safety improvement projects more efficiently. According to statistics released by the Jordan Traffic Institute (JTI) Jordan had 685 fatal crashes in 2017 with $76 \%$ of these crashes occurring in Amman of which $35 \%$ occur at intersections (JTI 2017). These facts calls for the need to establish a goal of reducing traffic related fatalities and severe injuries along the Jordanian roadway network (segments or intersections). Achieving this goal requires developing statistical models, referred to as Safety Performance Functions (SPFs) which provide realistic predictions of crash frequencies as a function of traffic volume and roadway geometries over a roadway network.

The roundabout is a form of intersection control which, if properly designed, can provide safety benefits when compared to stop and signal controlled intersections. 32 $\%$ of Amman's intersection crashes occur at roundabouts. Therefore, roundabouts have become increasingly popular in recent years leading to an increase in research into their effectiveness and safety performance.
This study provides an objective and unbiased method of measuring future safety for Amman roundabouts by developing SPFs to predict their crash frequencies. Comparing the predicted and observed crash frequency at a particular roundabout determines its relative safety.

\section{Literature review}

The first version of Highway Safety Manual (HSM) appeared in 2010 [1] , and it was a rescue to solve traffic safety issues on roads. The American Association of State Highway and Transportation Officials published it to give decision makers an idea on how to develop safety by anticipating the number of crashes depending on the road or intersection features (Peden, et al., 2004), then the SPF appeared. Road traffic crashes are discrete and nonnegative. They are usually over-dispersed with their variance higher than mean. Therefore, in order to account for overdispersion in the fitted models, negative binomial (NB) distribution is typically adopted (Srinivasan, et al. 2011). The general functional form of an SPF: $\mathrm{N}=\exp$ $(\alpha+\beta \times \ln \mathrm{AADT}+\gamma 1 \mathrm{X} 1+\gamma 2 \mathrm{X} 2+\ldots+\gamma \mathrm{nXn})$ Where: $\mathrm{N}$ : predicted average crash frequency, AADT: annual average daily traffic, $\mathrm{X} 1, \mathrm{X} 2, \ldots, \mathrm{Xn}=\mathrm{n}$ roadway

${ }^{a}$ Corresponding author: diana_alnabulsi90@hotmail.com 
geometric characteristics, and $\alpha, \beta, \gamma 1, \gamma 2, \ldots, \gamma \mathrm{n}=$ regression coefficients.

After that, the idyllic methods to develop the SPF models were Poisson regression and Binominal regression [2]. The negative binominal regression which is in the HSM adaptive method, was superior, since it doesn't have any limitations and its results are over dispersion, as Srinivasan, et al. (2011) described it and showed that standard errors of the parameter estimates to be tend understated [3] . A roundabout is a form of intersections and it doesn't have to be circular. It aims to control traffic without the need for stop signs [4]. The modern roundabout is a type of intersection that indirectly provides traffic control without the use of stop signs or traffic signals. These roundabouts, if properly designed, can provide safety and traffic flow benefits when compared to stop controlled and signal controlled intersections [5]. Montella (2011) conducted a study on 15 roundabouts in Italy and identified the crash contributory factors at roundabouts by using association rule analysis. Crashes that occurred could be attributed to either a single or multiple factors. Among 62 different contributory factors, geometric design was found to be the most frequent factor, occurring in almost 60 percent of total crashes. Markings and pavement were also major contributory factors that led to crashes. Several studies in the United States have indicated that roundabouts are a helpful means to reduce frequency and severity of crashes [6] . Isebrands, et al., (2012) carried out a study related to higher-speed rural roundabouts with stop control before the conversion and observed a reduction of 67 percent of total crashes and a reduction of 87 percent of injury crashes [7] . Persaud, et al., (2001) also reported that converting traditional intersections from stop sign or signal control decreased all crashes by 35 to 72 percent and decreased injury crashes by 74 to 88 percent [8]. Daniels, et al., (2010) explained that the safety performance of an intersection or a segment of roadway is identified through developing a relationship that includes all potential variables. They proved that crash frequency is not only related to the annual average daily volume (AADT) but is also affected, at least partly, by the geometric features of roundabouts [9].

\section{Methodology}

The study is carried out according to the following steps as shown below:

A. Select 20 roundabouts in Amman characterized with a high volume since previous research identified the AADT as the variable with the greatest impact on crash prediction using SPF.

B. Collection of comprehensive information for the selected roundabouts. This step involves the acquisition of the crash and geometric data. The crash data for each roundabout were provided by the Central Traffic Department and the geometric data are extracted from Google Earth.

C. Conducting a statistical analysis of the collected data to identify the relationship between the predicted numbers of crashes and a set of geometric and traffic characteristics. Data are compiled and analyzed using both Excel spreadsheets and SPSS IBM V19.

D. Developing SPF models that presents the crash frequency as a function of AADT and other related probable geometric variables

\section{Traffic and Geometric Characteristics of the Studied Sites}

The safety situation at the studied sites may be judged by the actual number of car crashes that have occurred over time. Fig. 1 shows the distribution of the observed crashes over four-year period $(2015-2018)$. It can be seen that most of the roundabouts (about 70\%) experienced an average of about 40 crashes per year. The descriptive statistics of the count of the studied roundabouts are shown in Table 1:

Table 1: Descriptive statistics for the analyzed $(\mathrm{N}=20)$ roundabouts

\begin{tabular}{|l|c|c|}
\hline \multirow{2}{*}{$\begin{array}{l}\text { Presence roundabout structure } \\
\text { Yes }\end{array}$} & Frequency & Percentage \\
\cline { 2 - 3 } & & 30 \\
\cline { 2 - 3 } $\begin{array}{l}\text { Presence of random police patrol } \\
\text { No } \\
\text { Yes }\end{array}$ & 14 & 70 \\
\cline { 2 - 3 } $\begin{array}{l}\text { Presence of pedestrian crossing structure } \\
\text { No }\end{array}$ Yes & 4 & 20 \\
\cline { 2 - 3 } & 16 & 80 \\
\hline Entry path angle, mean (SD) & & \\
\hline Entry path radius, mean (SD) & 12 & 60 \\
\hline Splitter island radius, mean (SD) & 8 & 40 \\
\hline $\begin{array}{l}\text { Roundabout central diameter (meters), mean } \\
\text { (SD) }\end{array}$ & & $69.5(26.4)$ \\
\hline
\end{tabular}




\begin{tabular}{|l|c|c|}
\hline $\begin{array}{l}\text { Roundabout inscribed diameter } \\
\text { (meters), mean (SD) }\end{array}$ & & $74.05(28.7)$ \\
\hline $\begin{array}{l}\text { Roundabout circular width diameter } \\
\text { (meters), mean (SD) }\end{array}$ & & $8.9(2.47)$ \\
\hline Number of roundabout legs, mean (SD) & & $4.4(0.6)$, median=4 \\
\hline $\begin{array}{l}\text { Number of circle legs categorized } \\
<=4 \text { legs } \\
>4 \text { legs }\end{array}$ & 14 & 70 \\
\hline Roundabout leg Entry width (meters) & 6 & 30 \\
\hline Annual average daily traffic Rate, mean (SD) & & $7.15(3.6)$ \\
\hline AADT 2015 & & $96931(42230)$ \\
\hline AADT 2016 & & $100687(44002)$ \\
\hline AADT 2017 & & $104730(45824)$ \\
\hline AADT 2018 & & $108924(47614)$ \\
\hline Roundabout annual car crashes & \\
\hline Total number of car crashes-2015, mean (SD) & & $129.55(81.8)$ \\
\hline Total number of car crashes-2016, mean (SD) & & $179.05(109.7)$ \\
\hline Total number of car crashes-2017, mean (SD) & & $188.05(142.5)$ \\
\hline Total number of car crashes-2018, mean (SD) & Frequency & \\
\hline
\end{tabular}

The above table shows that $70 \%$ of the studied roundabouts had structures like bridges and pedestrian crossing features whereas $30 \%$ had no such structures. $80 \%$ of the roundabouts, had a regular police patrols stationed on the roundabouts that control traffic on daily basis, whereas $20 \%$ had no police patrols. Assessing the analyzed bridges for the presence or absence of pedestrian crossing structures shows that:

$60 \%$ had no crossing structures, whereas $40 \%$ had a built crossing structure. The mean entry path radius was equal to $69.5+26.4$ meters. The mean distance for the bridges splitter island is calipered of $77.9+29.2$ meters. The mean roundabout central diameter for the analyzed circles was $58.3+29.6$ meters, whereas the mean inscribed diameter for the circles (meters) was $74.1+$ 28.7, with a circular roundabouts diameter of 8.9 meters, $\mathrm{SD}=2.5$ meters.

$70 \%$ of the studied roundabouts had four legs (exists), or less, and $30 \%$ have more than four legs, however, the mean legs number is centered at $4.4+0.6$ legs. The mean roundabouts entry width was equal 7.15 + 3.6. With regards to the measured annual car crashes, they suggest increasing trend:

The mean number of car crashes rises from 129.6 in 2015 to 165.1 in 2016 , then it continued to rise between the years 2017 and 2018 .

\section{Model Development}

The Generalized Mixed Methods R-M Analysis assumed the data of roundabouts across years are correlated, likewise for certain characteristics like the AADT, due to the presence of strong correlations between roundabout's repeated car crash measures. On this basis, a fixed effects model was requested, and the program was allowed to model the variance components between the twenty roundabouts, assuming that each roundabout may have different variances and co-variances (rise and fall) of their annual car crash crash's counts across the vector of time (years).

The variance component was also added in order to enhance the fit of the model via allowing each of the roundabouts to differ in their trajectories due to other factors inherent to their nature since they're geometrically different roundabouts.

The Generalized Mixed Methods requested modeling was a Negative binomial with logarithmic link due to the inherent skewness of car crash count variable, which follows the Poisson distribution family.

The model fit was assessed using the Baysian (AIC and BIC criteria).The over dispersion was assessed using methods like Scatterplots of observes versus predicted plots and predicted versus residual plots. Table 2, on the roundabouts measured annual crash rates across the four years between (2015-2018) for each roundabout. 
Table-2: Multivariate Mixed effects Generalized Negative Binomial Regression Analysis (N=20 roundabouts).

\begin{tabular}{|l|l|l|l|l|l|l|l|}
\hline \multicolumn{4}{|l|}{} & \multicolumn{2}{l|}{$\begin{array}{l}95 \% \text { C.I Exp } \\
\text { (Beta) }\end{array}$} & \\
\hline & $\begin{array}{l}\text { Beta } \\
\text { coefficient }\end{array}$ & $\begin{array}{l}\text { Std. } \\
\text { Err. }\end{array}$ & t-value & $\begin{array}{l}\text { Exponeniated } \\
\text { (Beta) }\end{array}$ & Lower & Upper & p-value \\
\hline (Intercept) & -3.150 & 2.200 & -1.430 & 0.043 & 0.001 & 3.480 & 0.157 \\
\hline (AADT/1000) Score & 0.011 & 0.002 & 6.290 & 1.011 & 1.007 & 1.014 & $<0.001$ \\
\hline $\begin{array}{l}\text { Roundabout entry } \\
\text { angle-degrees }\end{array}$ & 0.114 & 0.043 & 2.630 & 1.210 & 1.028 & 1.220 & 0.011 \\
\hline $\begin{array}{l}\text { Entry path radius } \\
\text { meters }\end{array}$ & -0.022 & 0.035 & -0.642 & 0.978 & 0.912 & 1.050 & 0.523 \\
\hline $\begin{array}{l}\text { Splitter radius - } \\
\text { meters }\end{array}$ & 0.047 & 0.060 & 0.785 & 1.048 & 0.930 & 1.182 & 0.435 \\
\hline $\begin{array}{l}\text { Pedestrian crossing } \\
\text { structure =yes } \\
\text { present }\end{array}$ & 0.124 & 0.137 & 0.908 & 1.131 & 0.862 & 1.490 & 0.367 \\
\hline Inscribed diameter & 0.051 & 0.060 & 0.866 & 1.052 & 0.936 & 1.184 & 0.390 \\
\hline $\begin{array}{l}\text { Central } \\
\text { diameter=meters }\end{array}$ & -0.033 & 0.013 & -2.540 & 0.097 & 0.943 & 0.993 & 0.013 \\
\hline Circulating width & -0.023 & 0.080 & -0.290 & 0.977 & 0.832 & 1.147 & 0.773 \\
\hline Entry width-meters & -0.011 & 0.070 & -1.560 & 0.897 & 0.781 & 1.031 & 0.124 \\
\hline $\begin{array}{l}\text { Number } \\
\text { roundabout Legs<=4 }\end{array}$ & 0.577 & 0.198 & 2.914 & 1.781 & 1.781 & 1.199 & 0.005 \\
\hline
\end{tabular}

The independent variables affecting the number of predicted crashes were found to include the Annual Average Daily Traffic (AADT) in addition to some geometrical features of the roundabout. The latter include roundabout entry angle, entry path radius splitter radius, presence or absence of pedestrians crossing structure, inscribed, central and circulating as well as entry width measures).

The model was specified via setting the time (years) as repeated measure, the subjects were the eighty records of individual yearly roundabouts measures. The roundabouts themselves were set as random factors and we requested the program to estimate a variance components model. The model was found to have the following form:

$$
\mathrm{N}=\mathrm{e} \beta 0 * \text { AADT } \beta 1 * \mathbf{e}(\boldsymbol{\beta 2} \mathbf{X} 2+\boldsymbol{\beta 3} \mathbf{X 3}+\ldots \ldots . .)
$$

Where:

X1: Roundabout entry Angle-degrees, X2: Entry path radius-meters, $\mathrm{X} 3$ : Splitter radius-meters. X4:
Pedestrian crossing structure $=$ yes present, X5: Inscribed diameter, X6: Central diameter (meters), X7: Circulating width, X8: Entry width-meters, X9: Number of circle legs (4 legs are used), $\left(\beta_{0}, \beta_{\mathrm{a}}\right)$ : Beta coefficient from table 2 .

The results showed the analysis model with the Generalized Mixed methods indicated that the for 4legs roundabout or less annual AADT, entry angle, correlated significantly but positively with higher crash rate growth. Whereas the RA central diameter correlated with lower crash rates, i.e., the correlation was significant and negative when accounting for the other predictors in the analysis $(p=0.013)$ a series parameters was used to evaluate and to determine how strong the statistical analysis was, such as AIC, BIC, $\mathrm{AICC}$ and BICC.

The model was validated by comparing the actual (Observed) and the predicted annual crashes producing a statistically significant relationship $\left(\mathrm{R}^{2}=0.91\right)$ as shown in fig. 2

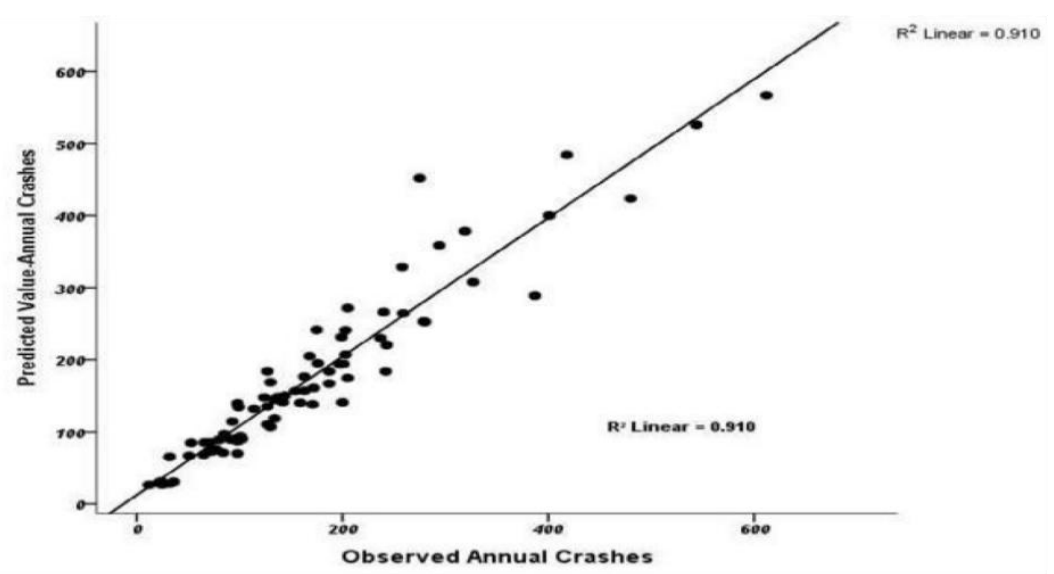

Figure 2: scatterplot of observed versus model predicted annual crashes 


\section{Conclusions}

SPFs have been used and proved to be effective safety measures in many countries but not yet implemented in Jordan. Developing SPFs using local data will provide more reliable crash frequency estimates than applying any calibration procedure.

This study involved the estimation of safety performance for roundabouts in Amman, through the development of SPFs to estimate the number of annual crashes at any given roundabout and to determine the impacts associated with various traffic and geometric characteristics,

However, the developed model tend to be reactionary and the approach of using only AADT has the limitation of being unable to identify the reason for a crash which requires a more proactive model. Therefore, a multivariate analysis was performed to determine how a variety of variables can contribute to crashes.

The results showed that the for 4-legs or less roundabouts, the factors of AADT and entry angle, correlate significantly and positively with higher crash rate, whereas the roundabout central diameter correlated with lower crash rates, i.e., the correlation was significant and negative when accounting for the other predictors in the analysis $(\mathrm{p}=0.013)$

\section{References}

1. American Association Of State Highway and Transportation Officials (AASHTO), (2010). Highway Safety Manual, 1st Edition, Washington, DC.

2. Peden M, Scurfield R, Sleet D, Mohan D, Hyder A, Jarawan E, Mathers C, (2004). The world report on road traffic injury prevention. WHO, Geneva.
3. Srinivasan, R., Haas, P., Dhakar, N., Hormel, R., Torbic, D. and Harwood, D., (2011), Development and Calibration of Highway Safety Manual Equations for Florida Conditions. Florida Department of Transportation.

4. Quezon T.E., Kumala T., and Aynetaw B., (2017), Evaluation on the Operational Characteristics of Gerji-Imperial Roundabout: A Case Study in Addis Ababa.

5. McIntosh k. (2011).Evaluating the Performance and Safety Effectiveness of Roundabouts, Opus International Consultants Inc. The Michigan Department of Transportation, USA.

6. Montella, A. (2011). Identifying crash contributory factors at urban roundabouts and using association rules to explore their relationships to different crash types. Crash Analysis \& Prevention, 43(4), 1451-1463

7. Isebrands, H., \& Hallmark, S. (2012). Statistical analysis and development of crash prediction model for roundabouts on high-speed rural roadways. Transportation Research Record, 2312(1), 3-13.

8. Lyon C., Persaud B., Hahn J. (2011). Safety Performance Functions for Ramp Terminals at Diamond Interchanges (Report No. CDOT 20119). Colorado Department of Transportation, Denver, Colorado.

9. Daniels, S., Brijs, T., Nuyts, E., \& Wets, G.(2010). "Explaining variation in safety Performance of roundabouts" Crash Analysis \& Prevention, Vol.42, No.2, Elsevier, pp. 393-402. 